\title{
Trypanosoma cruzi: ancestral genomes and population structure
}

\author{
Sérgio DJ Pena/ ${ }^{+}$, Carlos Renato Machado, Andréa Mara Macedo \\ Departamento de Bioquímica e Imunologia, Universidade Federal de Minas Gerais, Av. Antônio Carlos 6627, 31270-901 \\ Belo Horizonte, MG, Brasil
}

\begin{abstract}
Although the genome of Trypanosoma cruzi has been completely sequenced, little is known about its population structure and evolution. Since 1999, two major evolutionary lineages presenting distinct epidemiological characteristics have been recognised: T. cruzi I and T. cruzi II. We describe new and important aspects of the population structure of the parasite, and unequivocally characterise a third ancestral lineage that we propose to name T. cruzi III. Through a careful analysis of haplotypes (blocks of genes that are stably transmitted from generation to generation of the parasite), we inferred at least two hybridisation events between the parental lineages $\mathrm{T}$. cruzi II and $\mathrm{T}$. cruzi III. The strain CL Brener, whose genome was sequenced, is one such hybrid. Based on these results, we propose a simple evolutionary model based on three ancestral genomes, T. cruzi I, T. cruzi II and T. cruzi III. At least two hybridisation events produced evolutionarily viable progeny, and T. cruzi III was the cytoplasmic donor for the resulting offspring (as identified by the mitochondrial clade of the hybrid strains) in both events. This model should be useful to inform evolutionary and pathogenetic hypotheses regarding T. cruzi.
\end{abstract}

Key words: Trypanosoma cruzi - Chagas disease - genome - sex - evolution - pathogenesis

Two major anniversaries will dominate the biomedical sciences in Brazil in 2009: the bicentennial of the birth of Charles Darwin (and 150 year anniversary of the publication of "On the Origin of Species") and the 100th anniversary of Carlos Chagas' first report of the disease that carries his name. There is one nexus between these two great scientists; Adler (1959) and others after him proposed that Charles Darwin suffered from Chagas disease, which he might have contracted in Mendoza, Argentina in 1853. Independent of the truth or fiction of this hypothesis (which probably will never be settled), Darwin and Chagas will be linked together in the present article, where Trypanosoma cruzi and Chagas disease are analysed from an evolutionary point of view.

\section{The ecobiology of $T$. cruzi}

T. cruzi may be transmitted through wild hemiptera in a cycle that generally involves wild mammals (the "sylvatic" cycle) and may also be transmitted by homedwelling hemiptera in a cycle primarily involving humans and household animals (the so-called "domestic" cycle). The connection between the two ecosystems is made by infected rats, mice, bats, marsupials and other feral mammals. It is estimated that the parasite emerged as a species well over 150 million years ago, originally infecting primitive mammals dispersed throughout Laurasia and Gondwanaland, the regions that originated North and South America, respectively (Briones et al. 1999). Its first contact with humans occurred much more

\footnotetext{
Financial support: CNPq, PRONEX, FAPEMIG, WHO

+Corresponding author: spena@dcc.ufmg.br

Received 12 March 2009

Accepted 1 June 2009
}

recently, in the late Pleistocene (20,000-15,000 years ago), when humans first peopled the Americas. Thus, Homo sapiens is a very recent new host for T. cruzi. Convincing molecular evidence indicates the presence of $T$. cruzi DNA in mummies exhumed in Northern Chile and Southern Peru dating as far back as 9,000 years BP (Aufderheide et al. 2004).

The conventional mode of transmission of $T$. cruzi to humans is through the faeces of infected hematophagous triatomine bugs. Alternative modes of infection include blood transfusion, congenital transmission from infected mothers and the ingestion of contaminated foods. Thanks to intensive programmes of triatomine control, vectorial infection has been virtually abolished in Brazil and Argentina (Dias et al. 2002). Improved screening of blood-donors and early detection and treatment of congenital cases have also contributed to a decrease in the number of new cases. However, it would be a mistake to think that Chagas disease has been controlled. High levels of vector-borne transmission are still apparent in many areas and several countries where $T$. cruzi is endemic have yet to develop serious large-scale surveillance and intervention programmes (Dias et al. 2002). The migration of infected individuals presents the risk of new transmission in previously non-endemic regions, such as the United States (US) (Kirchhoff 1993). Furthermore, the ancient and wide-ranging sylvatic cycle maintains an enormous reservoir of the parasite that represents a threat to humans.

Recent studies have shown that in a non-endemic area of the Brazilian Atlantic coastal rainforest, $50 \%$ of the triatomine vectors and marsupials Didelphis marsupialis and Philander opossum (Jansen et al. 1999) as well as $52 \%$ of the golden lion tamarins and several other species of New World primates (Lisboa et al. 2004) were naturally infected with $T$. cruzi. Moreover, in the US T. cruzi has been found in $11.4 \%$ of opossums and $22 \%$ of 
raccoons, together with infected triatomine bugs in the state of Georgia (Pung et al. 1995). In certain areas of that state, up to $43 \%$ of the raccoons were infected (Pietrzak \& Pung 1998). Closer to the human domestic environment, Bradley et al. (2000) have shown that 3.6\% of rural hunting dogs in Oklahoma were seropositive for T. cruzi. Human infection from the sylvatic environment can occur either from sudden migration of hemiptera to the human environment, forced by the destruction of forests (Maguire et al. 1986) or by the ingestion of foods contaminated by hemipteran faeces or crushed insects (Shikanai-Yasuda et al. 1991, da Silva Valente et al. 1999). Thus, a complete understanding of the population structure of $T$. cruzi, especially the sylvatic cycle, will be indispensable for controlling the disease.

\section{Genetics and genomics of $T$. cruzi}

T. cruzi is diploid, with differentially-sized homologous chromosome pairs (Pedroso et al. 2003). Its genome has been recently sequenced (El-Sayed et al. 2005) and is estimated to be between 106.4-110.7 Mb in size (diploid). At least $50 \%$ of the T. cruzi genome is repetitive sequence, consisting mostly of large gene families of surface proteins, retrotransposons and subtelomeric repeats.

T. cruzi exhibits extensive and well-characterised intraspecific genetic diversity (Macedo \& Pena 1998, Tibayrenc 2003). Two major evolutionary lineages of the parasite, named T. cruzi I and T. cruzi II, have been identified (Satellite Meeting 1999). These lineages are very divergent, as revealed by several biological and molecular markers including isozymes (Miles 1978) and polymorphism in 24S $\alpha$ rDNA (GenBank accession $n^{\circ}$ L19411) and mini-exongene (GenBankaccessionn ${ }^{\circ}$ X62674)sequences (Fernandes et al. 1999). T. cruzi I and T. cruzi II strains belong predominantly to distinct ecological environments: thesylvaticanddomestictransmissioncyclesofChagasdisease, respectively (Briones etal. 1999, Zingales etal. 1999). T. cruzi I strains are characterised as containing zymodeme $\mathrm{Z1}$ (a zymodeme is a group of strains that have the same isozyme profile), 24S $\alpha$ rDNA and mini-exon group 2 , and induce low parasitism in human Chagas patients. In contrast, $T$. cruzi II strains are characterised as containing zymodeme $\mathrm{Z} 2,24 \mathrm{~S} \alpha$ rDNA and mini-exon group 1 , and cause human infections with high parasitemia in classic endemic areas (Zingales et al. 1999). In Brazil and Argentina, at least, T. cruzi II strains appear to be primarily responsible for the tissue lesions seen in Chagas disease (Di Noia et al. 2002, Freitas et al. 2005).

However, there are some parasite strains that cannot be properly grouped into any one of these two major lineages. Among these unclassified strains are those belonging to zymodeme Z3 (23) and hybrid strains characterised as rDNA group 1/2 (Souto et al. 1996, Stolf et al. 2003). Using isozymes and random amplification of polymorphic DNA (RAPD) typing, Brisse et al. (2000, 2001) proposed an alternative subdivision of $T$. cruzi strains into two major groups or DTUs (Discrete Typing Units) I and II. DTUI is a homogenous group corresponding to $T$. cruzi I. DTU II, however, is further subdivided into five sub-lineages (DTU IIa-e), each comprising one of the following reference strains: CanIII cll (IIa), Es- meraldo cl3 (IIb), M5631 cl5 (IIc), MN cl2 (IId) and CL Brener (IIe). DTU IIb corresponds to the major T. cruzi II lineage (Brisse et al. 2001). The extensive genetic diversity within each of these clades or sub-lineages can be unraveled by analyses of microsatellites and several other genomic markers (Macedo et al. 2004).

\section{Reproduction of $T$. cruzi}

Although capable of recombination in vitro (Gaunt et al. 2003), T. cruzi reproduces predominantly by binary fission. Consequently, its diploid nuclear genotype is transmitted en bloc to its progeny. Thus, T. cruzi presents extreme degrees of linkage disequilibrium, as shown through isozymes (Tibayrenc et al. 1986) and microsatellites (Oliveira et al. 1998), and exhibits a predominantly clonal population structure. Indeed, T. cruzi has been considered a prototypical clonal eukaryotic pathogenic microorganism (Tibayrenc \& Ayala 2002).

The occurrence of hybridisation in natural populations of $T$. cruzi was suggested by isozyme analyses (Bogliolo et al. 1996, Carrasco et al. 1996), restriction fragment length polymorphism of housekeeping genes (Higo et al. 2000), RAPD (Brisse et al. 2003) and genotype variations observed at chromosomal level (Brisse et al. 2003, Pedroso et al. 2003, Sturm et al. 2003) and has been confirmed by nucleotide sequencing (Machado and Ayala 2001, Augusto-Pinto et al. 2003). This discovery proved that sexual events definitely have occurred and have shaped the genetic structure of current $T$. cruzi populations. However, such genetic exchange events seem to have been rare enough to allow the propagation of clonal genotypes over long periods of time and wide geographical regions (Brisse et al. 2003). Genotyping of nuclear markers in $T$. cruzi has thus far been limited to the characterisation of multi-locus genotypes. To understand the evolutionary history of the species, it is desirable to dissect multi-locus genotypes into their constituent haploid genome blocks (haplotypes).

\section{Haplotype studies in $T$. cruzi}

For our haplotype studies, we initially typed a large number of monoclonal strains of T. cruzi with five nuclear CA-repeat microsatellites (Freitas et al. 2006). For our analysis we used as a metric the minimum number of mutational steps necessary to transform the microsatellite profile of one strain into that of another, assuming a stepwise mutation model for the evolution of the microsatellites. From the pairwise distance between the strains, we built a genetic distance matrix, which is pictorially depicted by the multidimensional scaling (MDS) plot shown in Fig. 1. Four clusters are clearly visible and identified by ellipsoids in the MDS plot. The identity of the clusters is revealed by the presence of the prototypical strains of Brisse et al. (2000): MDS-cluster A corresponds to DTU I or T. cruzi I, MDS-cluster C to DTU IIb or T. cruzi II, MDS-cluster B to DTU IIc and MDS-cluster BH to the DTU IId and IIe. Only three strains fell outside the four clusters: CanIII (DTU IIa), Dog Theis and 402.

It should be noted once more that $T$. cruzi is essentially a diploid organism. The multidimensional plot shown in Fig. 1 is based on the joint microsatellite typing of all the 


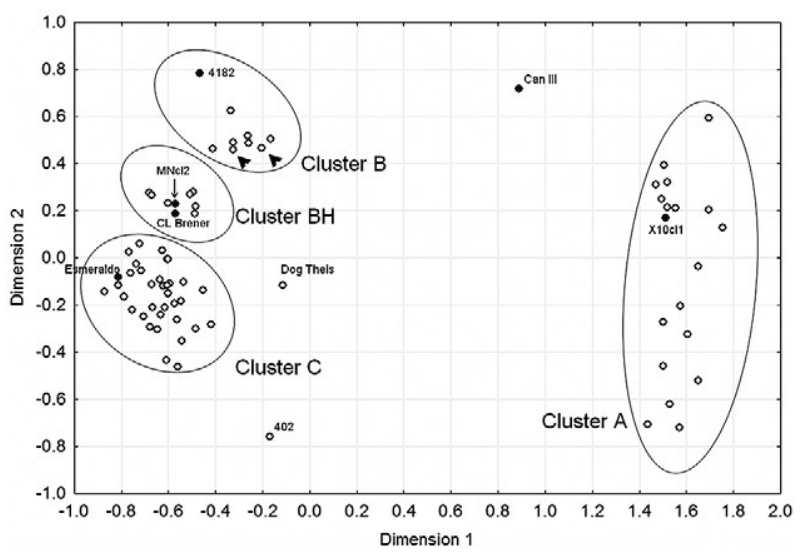

Fig. 1: multidimensional scaling plot of 75 Trypanosoma cruzi strains genotyped for five microsatellites. Only outliers and the prototypical strains of Brisse et al. (2000) 11 are named in the plot. Arrowheads indicate strains 222 and 115 . The strains in the regions delimited by ellipsoids are: multidimensional scaling (MDS)-cluster A: 1001, 1004, 1006, 1502, 1523, A83, A87, Col18/05, Colombiana, Cuíca, Cutia, D7, Gambacl1, Rb1, Rb2, Rb6, SE, X10c11, 402, Mas1cl1, 84, 207, 209, 239, 577, 578, 580, 581, 803, 1005, 1014, 1043, 1931, 183744, 169/1; MDS-cluster B: 115, 222, 226, 231, 3663, 3869, 4182, M5631c15; MDS-cluster BH: M6241c16, 167, 1022, c182, CL Brener, MNcl2, NR, SC43 cl1, SO3, Tulacl2; MDS-cluster C: 200pm, 84Ti, Be62, CPI11/94, CPI95/94, Esmeraldo, Gil, GLT564, GLT593, GMS, GOCH, Ig539, JAF, JG, JHF, JSM, MPD, OPS27/94, Tu18 cl11, Y. Modified from Freitas et al. (2006).

homologous chromosomes; in other words, this map is based on multi-local diploid genotypes of microsatellites. However, much more information could be acquired by separating the microsatellite alleles that are in each of the two homolog chromosomes, i.e., the two haplotypes.

If we were analysing a sexually reproducing organism, we would obtain two haplotypes for each chromosome pair. However, because of the predominant binary fission asexual reproduction of $T$. cruzi, extreme levels of linkage disequilibrium are present. Thus, the obtained haplotypes in fact represent whole haploid genomes, like the haploid gametes that unite during fertilisation to form a diploid organism.

To obtain the haplotypes, we ran the combined results of the microsatellite genotypes and 24S $\alpha$ rRNA gene polymorphisms through PHASE software (Stephens et al. 2001). This powerful programme uses a Bayesian strategy to estimate haplotypes from population genotype data. The programme identified no fewer than 141 different haplotypes in the 75 strains tested, corresponding to a haplotypic diversity of 0.993 (Freitas et al. 2006). The identified haplotypes were then subjected to a median joining analysis using NETWORK 3.1 software (Bandelt et al. 1999). The resulting multitude of plausible trees is best expressed by a network that displays alternative potential evolutionary paths (Fig. 2). Although the data are complex, three haplotypic clusters are clearly identifiable. We refer to these clusters as haplogroups X, $\mathrm{Y}$ and $\mathrm{Z}$. The three haplogroups are connected by long and unique paths, emphasising the great genetic distance

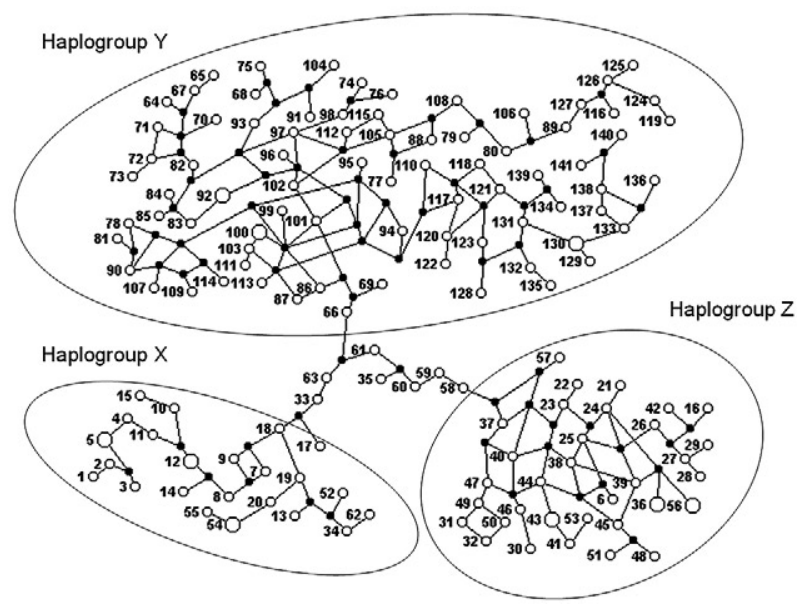

Fig. 2: neighbor-joining trees obtained from the sequences of three mitochondrial genes of Trypanosoma cruzi: cytochrome oxidase subunit II (COII) (Freitas et al. 2006), cytochrome b (CYb) (Brisse et al. 2003) and nicotinamida adenina dinucleotídeo dehydrogenase subunit 1 (ND1) (Machado \& Ayala 2002). The numbers in the three main branches indicate the percentage bootstrap values. For COII, the strains displayed are the following: clade A: 1004, 1006, 1502, Co118/05, Cuica, Cutia, RBI, RbII, SilvioX10; clade B: sublineage IIc 222, 231, 3869, M6241, Mn, sub-lineages IId and IIe - ClBrener, 1022, SO3, Tula; clade C: 1014, 1043, 169/1, 1931, 200pm, 209, 577, 578, 580, 581, 803, 84Ti, Be62, Esmeraldo, GLT593, GMS, Ig539, JG, JHF, Mas Cl1, MPD, TU18, Y. For CYb, the strains are as follows: clade A: Cuica, SC13, Tehuentepec, X10; clade B: sublineage IIc - M5631, M6241, X109/2, sub-lineages IId and IIe - 92.80, CL, Guateque, MN, SC43, Tulahuen, X57; clade C: CBB, Esmeraldo, TU18. For ND1, the strains are as follows: clade A: 133, 26, 85/818, A80, A92, CEPA, CUICA, CUTIA, Esquilo, MAV, OPS21, P0AC, P209, SABP3, SC13, SO34, TEH, V121, Vin, X10; clade B: sublineage IIc - CM, M6241, X109/2, X110/8, X9/3, sub-lineages IId and IIe - CL, 86/2036, 86-1, EPP, P251, P63, PSC-O, SO3, Tulahuen, VMV4; clade C: CBB, Esmeraldo, MBV, MCV, MSC2, TU18, X-300. Modified from Freitas et al. (2006).

between them. Seven haplotypes (numbers 33, 35, 58, 59, 60,61 and 63) belong to these "bridges" and hence could not be assigned to any of the haplogroups. We assigned these haplotypes to a fourth haplogroup that we called "I" for indeterminate.

We then assigned two haplogroups to each of the 75 strains to constitute a haplogroup "genotype" (Table). The results were very simple. All strains belonging to the DTU I lineage (MDS-cluster A) (Fig. 1) proved to be $\mathrm{Z} / \mathrm{Z}$, i.e., had two haplotypes belonging to haplogroup Z. Likewise, all the strains of DTU IIb (MDS-cluster C) (Fig. 1) had Y/Y genotypes and those of DTU IIc (MDScluster B) (Fig. 1) had X/X genotypes (Freitas et al. 2006). Thus we were able to identify three large groups of ancestral T. cruzi strains. The first had haplogroup "genotype" Z/Z, corresponding to T. cruzi I. The second had haplogroup "genotype" $\mathrm{Y} / \mathrm{Y}$ and clearly corresponded to T. cruzi II. The most significant finding of our study was the identification of the $\mathrm{X} / \mathrm{X}$ cluster, which corresponds exactly to the $T$. cruzi strains that belong to zymodeme Z3 found by Miles et al. (1978) and which do not fit into the dichotomous T. cruzi I/T. cruzi II model proposed in 
TABLE

Nuclear and mitochondrial markers of Trypanosoma cruzi

\begin{tabular}{|c|c|c|c|c|}
\hline Strains & $\mathrm{COII}^{a}$ & Clusters $^{b}$ & Haplotypes $^{c}$ & Haplogroups $^{d}$ \\
\hline A83 & A & A & $25 / 26$ & $\mathrm{Z} / \mathrm{Z}$ \\
\hline A87 & A & A & $27 / 28$ & $\mathrm{Z} / \mathrm{Z}$ \\
\hline Col18/05 & A & A & $21 / 56$ & $\mathrm{Z} / \mathrm{Z}$ \\
\hline Colombiana & A & A & $24 / 56$ & $\mathrm{Z} / \mathrm{Z}$ \\
\hline Cuíca & A & A & $31 / 49$ & $\mathrm{Z} / \mathrm{Z}$ \\
\hline Cutia & A & A & $44 / 47$ & $\mathrm{Z} / \mathrm{Z}$ \\
\hline D7 & A & A & $6 / 29$ & $\mathrm{Z} / \mathrm{Z}$ \\
\hline Gamba cl1 & A & A & $30 / 46$ & $\mathrm{Z} / \mathrm{Z}$ \\
\hline $\mathrm{Rb} 1$ & A & A & $36 / 57$ & $\mathrm{Z} / \mathrm{Z}$ \\
\hline $\mathrm{Rb} 2$ & A & A & $16 / 36$ & $\mathrm{Z} / \mathrm{Z}$ \\
\hline Rb6 & A & A & $38 / 41$ & $\mathrm{Z} / \mathrm{Z}$ \\
\hline SE & A & A & $48 / 53$ & $\mathrm{Z} / \mathrm{Z}$ \\
\hline SilvioX10cl1 & A & A & $32 / 50$ & $\mathrm{Z} / \mathrm{Z}$ \\
\hline 1001 & A & A & $43 / 43$ & $\mathrm{Z} / \mathrm{Z}$ \\
\hline 1004 & A & A & $23 / 37$ & $\mathrm{Z} / \mathrm{Z}$ \\
\hline 1006 & A & A & $22 / 40$ & $\mathrm{Z} / \mathrm{Z}$ \\
\hline 1502 & A & A & $39 / 45$ & $\mathrm{Z} / \mathrm{Z}$ \\
\hline 1523 & A & A & $42 / 51$ & $\mathrm{Z} / \mathrm{Z}$ \\
\hline 115 & $\mathrm{~B}$ & $\mathrm{~B}$ & $7 / 19$ & $\mathrm{X} / \mathrm{X}$ \\
\hline 222 & $\mathrm{~B}$ & $\mathrm{~B}$ & $1 / 20$ & $\mathrm{X} / \mathrm{X}$ \\
\hline 226 & $\mathrm{~B}$ & $\mathrm{~B}$ & $9 / 18$ & $\mathrm{X} / \mathrm{X}$ \\
\hline 231 & B & B & $11 / 17$ & $\mathrm{X} / \mathrm{X}$ \\
\hline 3663 & B & $\mathrm{B}$ & $8 / 10$ & $\mathrm{X} / \mathrm{X}$ \\
\hline 3869 & $\mathrm{~B}$ & B & $13 / 14$ & $\mathrm{X} / \mathrm{X}$ \\
\hline 4182 & B & B & $15 / 62$ & $\mathrm{X} / \mathrm{X}$ \\
\hline M5631cl5 & B & B & $12 / 12$ & $\mathrm{X} / \mathrm{X}$ \\
\hline M6241cl6 & B & B & $33 / 34$ & $\mathrm{X} / \mathrm{X}$ \\
\hline 167 & B & $\mathrm{BH}$ & 4/99 & $\mathrm{X} / \mathrm{Y}$ \\
\hline 182 & B & $\mathrm{BH}$ & $5 / 108$ & $\mathrm{X} / \mathrm{Y}$ \\
\hline 1022 & B & $\mathrm{BH}$ & $2 / 102$ & $\mathrm{X} / \mathrm{Y}$ \\
\hline CLBrener & B & $\mathrm{BH}$ & $5 / 100$ & $\mathrm{X} / \mathrm{Y}$ \\
\hline $\operatorname{Mncl} 2$ & B & $\mathrm{BH}$ & $52 / 133$ & $\mathrm{X} / \mathrm{Y}$ \\
\hline NR & B & $\mathrm{BH}$ & $55 / 130$ & $\mathrm{X} / \mathrm{Y}$ \\
\hline SC43 cl1 & B & $\mathrm{BH}$ & $54 / 129$ & $\mathrm{X} / \mathrm{Y}$ \\
\hline $\mathrm{SO} 3$ & B & $\mathrm{BH}$ & $54 / 130$ & $\mathrm{X} / \mathrm{Y}$ \\
\hline Tula cl2 & B & $\mathrm{BH}$ & $3 / 103$ & $\mathrm{X} / \mathrm{Y}$ \\
\hline CanIII cll & B & outlier & $58 / 59$ & $\mathrm{I} / \mathrm{I}$ \\
\hline Be62 & $\mathrm{C}$ & $\mathrm{C}$ & $88 / 105$ & $\mathrm{Y} / \mathrm{Y}$ \\
\hline CPI95/94 & $\mathrm{C}$ & $\mathrm{C}$ & $110 / 114$ & $\mathrm{Y} / \mathrm{Y}$ \\
\hline Esmeraldo & $\mathrm{C}$ & $\mathrm{C}$ & $109 / 135$ & $\mathrm{Y} / \mathrm{Y}$ \\
\hline Gil & $\mathrm{C}$ & $\mathrm{C}$ & $77 / 79$ & $\mathrm{Y} / \mathrm{Y}$ \\
\hline GLT564 & $\mathrm{C}$ & $\mathrm{C}$ & $97 / 98$ & $\mathrm{Y} / \mathrm{Y}$ \\
\hline GLT593 & $\mathrm{C}$ & $\mathrm{C}$ & $74 / 131$ & $\mathrm{Y} / \mathrm{Y}$ \\
\hline GMS & $\mathrm{C}$ & $\mathrm{C}$ & $90 / 131$ & $\mathrm{Y} / \mathrm{Y}$ \\
\hline $\mathrm{GOCH}$ & $\mathrm{C}$ & $\mathrm{C}$ & $81 / 126$ & $\mathrm{Y} / \mathrm{Y}$ \\
\hline $\operatorname{Ig} 539$ & $\mathrm{C}$ & $\mathrm{C}$ & $123 / 125$ & $\mathrm{Y} / \mathrm{Y}$ \\
\hline JAF & $\mathrm{C}$ & $\mathrm{C}$ & $67 / 92$ & $\mathrm{Y} / \mathrm{Y}$ \\
\hline $\mathrm{JG}$ & $\mathrm{C}$ & $\mathrm{C}$ & $82 / 92$ & $\mathrm{Y} / \mathrm{Y}$ \\
\hline JHF & $\mathrm{C}$ & $\mathrm{C}$ & $83 / 84$ & $\mathrm{Y} / \mathrm{Y}$ \\
\hline JSM & $\mathrm{C}$ & $\mathrm{C}$ & $65 / 95$ & $\mathrm{Y} / \mathrm{Y}$ \\
\hline Mas1 cl1 & $\mathrm{C}$ & $\mathrm{C}$ & $63 / 136$ & $\mathrm{Y} / \mathrm{I}$ \\
\hline MPD & $\mathrm{C}$ & $\mathrm{C}$ & $64 / 76$ & $\mathrm{Y} / \mathrm{Y}$ \\
\hline OPS27/94 & $\mathrm{C}$ & $\mathrm{C}$ & $134 / 141$ & $\mathrm{Y} / \mathrm{Y}$ \\
\hline Tu18 cl11 & $\mathrm{C}$ & $\mathrm{C}$ & $137 / 138$ & $\mathrm{Y} / \mathrm{Y}$ \\
\hline Y & $\mathrm{C}$ & $\mathrm{C}$ & $86 / 87$ & $\mathrm{Y} / \mathrm{Y}$ \\
\hline 84 & $\mathrm{C}$ & $\mathrm{C}$ & $66 / 78$ & $\mathrm{Y} / \mathrm{Y}$ \\
\hline $84 \mathrm{Ti}$ & $\mathrm{C}$ & $\mathrm{C}$ & $71 / 73$ & $\mathrm{Y} / \mathrm{Y}$ \\
\hline
\end{tabular}

\begin{tabular}{lcccc} 
Strains & COII $^{a}$ & Clusters $^{b}$ & Haplotypes $^{c}$ & Haplogroups $^{d}$ \\
\hline $169 / 1$ & $\mathrm{C}$ & $\mathrm{C}$ & $85 / 94$ & $\mathrm{Y} / \mathrm{Y}$ \\
$200 \mathrm{pm}$ & $\mathrm{C}$ & $\mathrm{C}$ & $112 / 115$ & $\mathrm{Y} / \mathrm{Y}$ \\
207 & $\mathrm{C}$ & $\mathrm{C}$ & $75 / 139$ & $\mathrm{Y} / \mathrm{Y}$ \\
209 & $\mathrm{C}$ & $\mathrm{C}$ & $69 / 101$ & $\mathrm{Y} / \mathrm{Y}$ \\
239 & $\mathrm{C}$ & $\mathrm{C}$ & $80 / 96$ & $\mathrm{Y} / \mathrm{Y}$ \\
577 & $\mathrm{C}$ & $\mathrm{C}$ & $89 / 124$ & $\mathrm{Y} / \mathrm{Y}$ \\
578 & $\mathrm{C}$ & $\mathrm{C}$ & $122 / 127$ & $\mathrm{Y} / \mathrm{Y}$ \\
580 & $\mathrm{C}$ & $\mathrm{C}$ & $117 / 118$ & $\mathrm{Y} / \mathrm{Y}$ \\
581 & $\mathrm{C}$ & $\mathrm{C}$ & $113 / 116$ & $\mathrm{Y} / \mathrm{Y}$ \\
803 & $\mathrm{C}$ & $\mathrm{C}$ & $72 / 119$ & $\mathrm{Y} / \mathrm{Y}$ \\
1005 & $\mathrm{C}$ & $\mathrm{C}$ & $100 / 106$ & $\mathrm{Y} / \mathrm{Y}$ \\
1014 & $\mathrm{C}$ & $\mathrm{C}$ & $68 / 93$ & $\mathrm{Y} / \mathrm{Y}$ \\
1043 & $\mathrm{C}$ & $\mathrm{C}$ & $107 / 128$ & $\mathrm{Y} / \mathrm{Y}$ \\
1931 & $\mathrm{C}$ & $\mathrm{C}$ & $91 / 104$ & $\mathrm{Y} / \mathrm{Y}$ \\
183744 & $\mathrm{C}$ & $\mathrm{C}$ & $120 / 121$ & $\mathrm{Y} / \mathrm{Y}$ \\
CPI11/94 & $\mathrm{C}$ & $\mathrm{C}$ & $111 / 140$ & $\mathrm{Y} / \mathrm{Y}$ \\
Dog Theis & $\mathrm{C}$ & outlier & $60 / 61$ & $\mathrm{I} / \mathrm{I}$ \\
402 & $\mathrm{C}$ & outlier & $35 / 70$ & $\mathrm{Y} / \mathrm{I}$
\end{tabular}

$a$ : restriction fragment length polymorphism typing of the $T$. cruzi cytochrome oxidase subunit II (COII) gene; $b$ : clusters of strains generated by multidimensional scaling analysis; $c$ : haplotypes inferred by PHASE; $d$ : clusters of haplotypes in the Network. Modified from Freitas et al. (2006).

1999. We suggest that this is a third phylogenetic lineage of T. cruzi and should be designated T. cruzi III.

Interestingly, the strains in cluster $\mathrm{BH}$ all had $\mathrm{X} / \mathrm{Y}$ genotypes, confirming their hybrid nature and indicating that they were derived from recombination events between ancestral types $\mathrm{Y} / \mathrm{Y}$ and X/X, i.e., T. cruzi II and T. cruzi III. Due to the way that PHASE identifies haplotypes, proximity of haplotype numbers is highly correlated with genetic proximity. Hybrid strains 167, 1022, 182, CL Brener and Tulacl2 have genotypes 4/99, 2/102, $5 / 108,5 / 100$ and 3/103, respectively, and form one group, while strains MNcl2, NR, SC43cl1, and SO3 have genotypes 52/133, 55/130, 54/129 and 54/130 and form another group. Notably, these groups are equivalent to sub-lineages IIe and IId of Brisse et al. (2000). This suggests that at least two independent hybridisations occurred, presumably followed by clonal microdifferentiation.

The classification of T. cruzi into three major phylogenetic trunks does not exhaust all ancestral possibilities. The strains Can III [genotype I/I, cytochrome oxidase subunit II (COII) B], Dog Theis (genotype I/I, COII C), 402 and Mas1cl1 (both genotype I/Y, COII C) share haplotypes with haplogroup I. Three of these four strains are located outside MDS clusters in Fig. 1A, which may suggest the existence of yet other phylogenetic lineages in T. cruzi.

\section{Mitochondrial DNA studies}

The extreme levels of linkage disequilibrium in the genome of $T$. cruzi not only cause the association of all nuclear markers into haploid genotypes, but also create strong associations between nuclear markers and mitochondrial genotypes. The latter are known to be 
uniparental (by convention, the maternal gamete is the mitochondrial donor) and functionally haploid. Indeed, Gaunt et al. (2003) have shown that the hybridisation of T. cruzi strains involves only nuclear genomes and that mitochondrial fusion does not occur.

We studied the sequences of large portions of the maxicircle-encoded COII gene (Freitas et al. 2006) as well as cytochrome b (Brisse et al. 2003) and nicotinamide adenine dinucleotide dehydrogenase subunit 1 (Machado $\&$ Ayala 2001). The neighbour-joining trees generated for each of these regions are shown in Fig. 3. All trees was had very similar topologies, consisting of three tightly clustered sets of strains, separated by very large genetic distances, permitting the straightforward allocation of $T$. cruzi strains into three mitochondrial clades. For simplicity, we called these clades clusters A, B, and C.

It was most rewarding to observe that our MDS clusters (Fig. 1) corresponded perfectly to their homonymous mitochondrial clades, i.e., MDS cluster A was composed of the same strains that belonged to haplogroup $\mathrm{Z} / \mathrm{Z}$ and to mitochondrial clade $\mathrm{A}$, MDS cluster $\mathrm{C}$ was composed of the same strains that belonged to haplogroup $\mathrm{Y} / \mathrm{Y}$ and to mitochondrial clade $\mathrm{C}$ and MDS cluster B was composed of the same strains that belonged to haplogroup $\mathrm{X} / \mathrm{X}$ and to mitochondrial clade $\mathrm{B}$. Thus, the results of the mitochondrial sequencing strongly confirm the existence of the T. cruzi III phylogenetic group.

The MDS cluster BH contained the strains belonging to the hybrid sub-lineages IId and IIe (Brisse et al. 2000), all of which fall within mitochondrial clade B. Thus, the strains of sub-lineages IId and IIe are not only produced by hybridisations between $T$. cruzi II and T. cruzi III, but both have the same mitochondrial donor, T. cruzi III.

\section{An evolutionary model}

Based on our results, we propose that three ancestral genomes, T. cruzi I, T. cruzi II and T. cruzi III (Fig. 4), existed in the distant past. It is interesting to note that this proposal matches the initial suggestion made by Miles et al. (1978) almost 30 years ago on the basis of isozyme studies. It is likely that $T$. cruzi II and $T$. cruzi III had overlapping ecological niches and thus the condi-

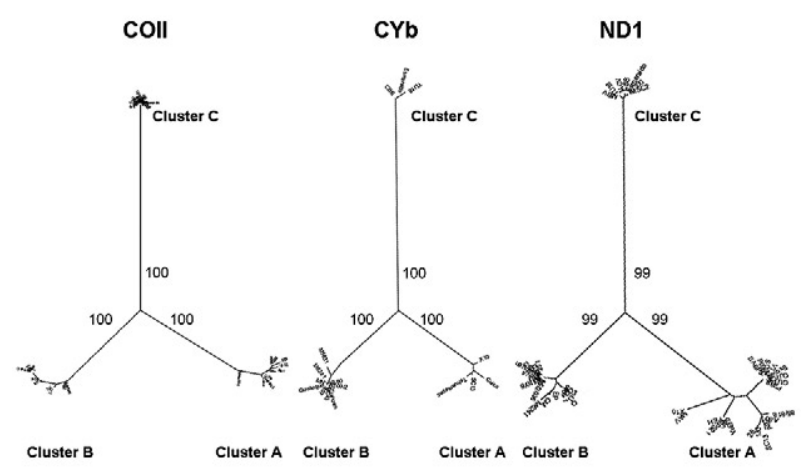

Fig. 3: median joining network of the haplotypes identified by the PHASE software.

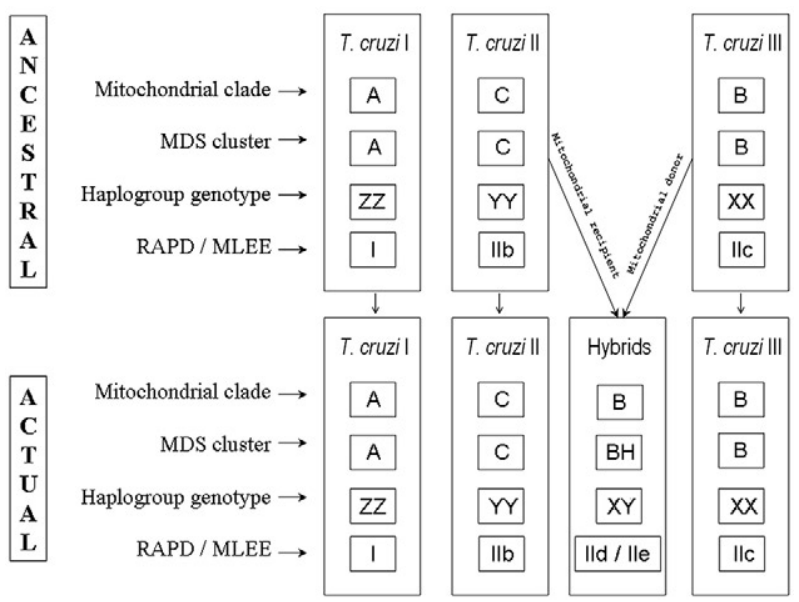

Fig. 4: diagram depicting the proposed model for the evolution of Trypanosoma cruzi strains. Modified from Freitas et al. (2006).

tions necessary for hybridisation were in place. At least two hybridisation events produced evolutionarily viable progeny. In both events, the cytoplasmic donor for the resulting offspring (as identified by the mitochondrial clade of the hybrid strains) was T. cruzi III.

The existence of strains that cannot be accommodated into this scenario, i.e., CanIII [sub-lineage IIa of Brisse et al. (2000)] and Dog Theis, suggests additional complexity in the evolutionary history of $T$. cruzi. Other alternative models have been proposed for its population structure (Westenberger et al. 2005), but we will not discuss them fully here as they are not based on the novel high resolution haplotypic analysis presented in our work (Freitas et al. 2006).

The fact that the same population structure of T. cruzi is predicted with different molecular markers, such as isozymes (Miles et al. 1978), RAPD (Brisse et al. 2000, 2003), microsatellites (Oliveira et al. 1998) and several other nuclear sequences (Fernandes et al. 1999, Zingales et al. 1999, Machado \& Ayala 2001, August-Pinto et al. 2003), and mitochondrial markers (Machado \& Ayala 2001, Brisse et al. 2003, Freitas et al. 2006), bears witness to its extreme stability. Although it has been shown conclusively in our study and also by others (Machado \& Ayala 2001, Brisse et al. 2003) that hybridisation events have occurred in the evolutionary history of T. cruzi, they seem to have been subsequently stabilised by strong clonal propagation (Macedo \& Pena 1998, Tibayrenc 2003).

\section{REFERENCES}

Adler S 1959. Darwin's illness. Nature 184: 1102-1104.

Aufderheide AC, Salo W, Madden M, Streitz J, Buikstra, Guhl F, Arriaza B, Renier C, Wittmers LE Jr, Fornaciari G, Allison M 2004. A 9,000-year record of Chagas' disease. Proc Natl Acad Sci USA 101: 2034-2039.

Augusto-Pinto L, Teixeira SM, Pena SD, Machado CR 2003. Singlenucleotide polymorphisms of the Trypanosoma cruzi MSH2 gene support the existence of three phylogenetic lineages presenting differences in mismatch-repair efficiency. Genetics 164: 117-126. 
Bandelt HK, Forster P, Rohl A 1999. Median-joining networks for inferring intraspecific phylogenies. Mol Biol Evol 16: 37-48.

Bogliolo AR, Lauria-Pires L, Gibson WC 1996. Polymorphisms in Trypanosoma cruzi: evidence of genetic recombination. Acta Trop 61: 31-40.

Bradley KK, Bergman DK, Woods JP, Crutcher JM, Kirchhoff LV 2000. Prevalence of American trypanosomiasis Chagas disease among dogs in Oklahoma. $J$ Am Vet Med Assoc 217: 1853-1857.

Briones MR, Souto RP, Stolf BS, Zingales B 1999. The evolution of two Trypanosoma cruzi subgroups inferred from $r R N A$ genes can be correlated with the interchange of American mammalian faunas in the Cenozoic and has implications to pathogenicity and host specificity. Mol Biochem Parasitol 104: 219-232.

Brisse S, Dujardin JC, Tibayrenc M 2000. Identification of six Trypanosoma cruzi phylogenetic lineages by random amplified polymorphic DNA and multilocus enzyme eletrophoresis. Int $J$ Parasitol 30: 35-44.

Brisse S, Henriksson J, Barnabe C, Douzery EJ, Berkvens D, Serrano M, De Carvalho MR, Buck GA, Dujardin JC, Tibayrenc M 2003. Evidence for genetic exchange and hybridization in Trypanosoma cruzi based on nucleotide sequences and molecular karyotype. Infect Genet Evol 2: 173-183.

Brisse S, Verhoef J, Tibayrenc M 2001. Characterization of large and small subunit rRNA and mini-exon genes further supports the distinction of six Trypanosoma cruzi lineages. Int J Parasitol 31: 1218-1226.

Carrasco HJ, Frame IA, Valente SA, Miles MA 1996. Genetic exchange as a possible source of genomic diversity in sylvatic populations of Trypanosoma cruzi. Am J Trop Med Hyg 54: 418-224.

da Silva Valente SA, de Costa Valente V, Neto HF 1999. Considerations on the epidemiology and transmission of Chagas disease in the Brazilian Amazon. Mem Inst Oswaldo Cruz 94 (Suppl. I): 395-398.

Dias JC, Silveira AC, Schofield CJ 2002. The impact of Chagas disease control in Latin America: a review. Mem Inst Oswaldo Cruz 97: 603-612.

Di Noia JM, Buscaglia CA, De Marchi CR, Almeida IC, Frasch AC 2002. A Trypanosoma cruzi small surface molecule provides the first immunological evidence that Chagas' disease is due to a single parasite lineage. J Exp Med 195: 401-413.

El-Sayed NM, Myler PJ, Bartholomeu DC, Nilsson D, Aggarwal G, Tran AN, Ghedin E, Worthey EA, Delcher AL, Blandin G, Westenberger SJ, Caler E, Cerqueira GC, Branche C, Haas B, Anupama A, Arner E, Aslund L, Attipoe P, Bontempi E, Bringaud F, Burton P, Cadag E, Campbell DA, Carrington M, Crabtree J, Darban H, da Silveira JF, de Jong P, Edwards K, Englund PT, Fazelina G, Feldblyum T, Ferella M, Frasch AC, Gull K, Horn D, Hou L, Huang Y, Kindlund E, Klingbeil M, Kluge S, Koo H, Lacerda D, Levin MJ, Lorenzi H, Louie T, Machado CR, McCulloch R, McKenna A, Mizuno Y, Mottram JC, Nelson S, Ochaya S, Osoegawa K, Pai G, Parsons M, Pentony M, Pettersson U, Pop M, Ramirez JL, Rinta J, Robertson L, Salzberg SL, Sanchez DO, Seyler A, Sharma R, Shetty J, Simpson AJ, Sisk E, Tammi MT, Tarleton R, Teixeira S, Van Aken S, Vogt C, Ward PN, Wickstead B, Wortman J, White O, Fraser CM, Stuart KD, Andersson B 2005. The genome sequence of Trypanosoma cruzi, etiologic agent of Chagas disease. Science 309: 409-415.

Fernandes O, Santos S, Junqueira A, Jansen A, Cupolillo E, Campbell D, Zingales B, Coura JR 1999. Populational heterogeneity of Brazilian Trypanosoma cruzi isolates revealed by the mini-exon and ribosomal spacers. Mem Inst Oswaldo Cruz 94: 195-197.
Freitas JM, Augusto-Pinto L, Pimenta JR, Bastos-Rodrigues L, Gonçalves VF, Teixeira SM, Chiari E, Junqueira AC, Fernandes O, Macedo AM, Machado CR, Pena SD 2006. Ancestral genomes, sex and the population structure of Trypanosoma cruzi. PLoS Pathog 2: e24.

Freitas JM, Lages-Silva E, Crema E, Pena SD, Macedo AM 2005. Real time PCR strategy for the identification of major lineages of Trypanosoma cruzi directly in chronically infected human tissues. Int J Parasitol 35: 411-417.

Gaunt MW, Yeo M, Frame IA, Stothard JR, Carrasco HJ, Taylor MC, Mena SS, Veazey P, Miles GA, Acosta N, de Arias AR, Miles MA 2003. Mechanism of genetic exchange in American trypanosomes. Nature 421: 936-939.

Higo H, Yanagi T, Matta V, Agatsuma, Cruz-Reyes A, Uyema N, Monroy C, Kanbara H, Tada I 2000. Genetic structure of Trypanosoma cruzi in American continents: special emphasis on sexual reproduction in Central America. Parasitology 121: 403-408.

Jansen AM, Santos de Pinho AP, Lisboa CV, Cupolillo E, Mangia RH, Fernandes O 1999. The sylvatic cycle of Trypanosoma cruzi: a still unsolved puzzle. Mem Inst Oswaldo Cruz 94 (Suppl. I): 203-204.

Kirchhoff LV 1993. American trypanosomiasis Chagas' disease. A tropical disease now in the United States. $N$ Engl J Med 329: 639-644.

Lisboa CV, Mangia RH, De Lima NR, Martins A, Dietz J, Baker AJ, Ramon-Miranda CR, Ferreira LF, Fernandes O, Jansen AM 2004. Distinct patterns of Trypanosoma cruzi infection in Leontopithecus rosalia in distinct Atlantic coastal rainforest fragments in Rio de Janeiro - Brazil. Parasitology 129: 703-711.

Macedo AM, Machado CR, Oliveira RP, Pena SDJ 2004. Trypanosoma cruzi: genetic structure of populations and relevance of genetic variability to the pathogenesis of Chagas disease. Mem Inst Oswaldo Cruz 99: 1-12.

Macedo AM, Pena SDJ 1998. Genetic variability of Trypanosoma cruzi: implications for the pathogenesis of Chagas' disease. Parasitol Today 14: 119-124.

Machado CA, Ayala FJ 2001. Nucleotide sequences provide evidence of genetic exchange among distantly related lineages of Trypanosoma cruzi. Proc Natl Acad Sci 98: 7396-7401.

Maguire JH, Hoff R, Sleigh AC, Mott KE, Ramos NB, Sherlock IA 1986. An outbreak of Chagas' disease in Southwestern Bahia, Brazil. Am J Trop Med Hyg 35: 931-936.

Miles MA, Souza A, Povoa M, Shaw JJ, Lainson R, Toyle PJ 1978. Isozymic heterogeneity of Trypanosoma cruzi in the first autochthonous patients with Chagas' disease in Amazonian Brazil. $\mathrm{Na}$ ture 272: 819-821.

Oliveira RP, Broude NE, Macedo AM, Cantor CR, Smith CL, Pena SD 1998. Probing the genetic population structure of Trypanosoma cruzi with polymorphic microsatellites. Proc Natl Acad Sci USA 95: 3776-3780.

Pedroso A, Cupolillo E, Zingales B 2003. Evaluation of Trypanosoma cruzi hybrid stocks based on chromosomal size variation. Mol Biochem Parasitol 129: 79-90.

Pietrzak SM, Pung OJ 1998. Trypanosomiasis in raccoons from Georgia. J Wildl Dis 34: 132-136.

Pung OJ, Banks CW, Jones DN, Krissinger MW 1995. Trypanosoma cruzi in wild raccoons, opossums and triatomine bugs in southeast Georgia, USA. J Parasitol 81: 324-326.

Satellite Meeting 1999. Recommendations from an international symposium to commemorate the 90th anniversary of the discovery of Chagas disease, April 11-16 1999, Rio de Janeiro, Brazil. Mem Inst Oswaldo Cruz 94: 429-432. 
Shikanai-Yasuda MA, Marcondes CB, Guedes LA, Siqueira GS, Barone AA, Dias JC, Amato Neto V, Tolezano JE, Peres BA, Arruda Júnior ER 1991. Possible oral transmission of acute Chagas' disease in Brazil. Rev Inst Med Trop São Paulo 33: 351-357.

Souto RP, Fernandes O, Macedo AM, Campbell DA, Zingales B 1996. DNA markers define two major phylogenetic lineages of Trypanosoma cruzi. Mol Biochem Parasitol 83: 141-152.

Stephens M, Smith NJ, Donnelly P 2001. A new statistical method for haplotype reconstruction from population data. Am J Hum Genet 68: 978-989.

Stolf BS, Souto RP, Pedroso A, Zingales B 2003. Two types of ribosomal RNA genes in hybrid Trypanosoma cruzi strains. Mol Biochem Parasitol 126: 73-80.

Sturm NR, Vargas NS, Westenberger SJ, Zingales B, Campbell DA 2003. Evidence for multiple hybrid groups in Trypanosoma cruzi. Int J Parasitol 33: 269-279.

Tibayrenc M 1996. Towards a unified evolutionary genetics of micro- organisms. Аnпu Rev Microbiol 50: 401-429.

Tibayrenc M 2003. Genetic subdivisions within Trypanosoma cruzi discrete typing units and their relevance for molecular epidemiology and experimental evolution. Kinetoplastid Biol Dis 28: 2-12.

Tibayrenc M, Ayala FJ 2002. The clonal theory of parasitic protozoa: 12 years on. Trends Parasitol 18: 405-410.

Tibayrenc M, Ward P, Moya A, Ayala FJ 1986. Natural populations of Trypanosoma cruzi, the agent of Chagas' disease, have a complex multiclonal structure. Proc Nat Acad Sci USA 83: 115-119.

Westenberger SJ, Barnabé C, Campbell DA, Sturm NR 2005. Two hybridization events define the population structure of Trypanosoma cruzi. Genetics 171: 527-543.

Zingales B, Stolf BS, Souto RP, Fernandes O, Briones MR 1999. Epidemiology, biochemistry and evolution of Trypanosoma cruzi lineages based on ribosomal RNA sequences. Mem Inst Oswaldo Cruz 94: 159-164. 